Journal of Transport and Land Use 1:1 (Summer 2008) pp. 41-63

Available at http://jtlu.org

\title{
JTLU
}

\section{A use-based measure of accessibility to linear features to predict urban trail use}

\author{
John R. Ottensmann and Greg Lindsey \\ Indiana University-Purdue University Indianapolis ${ }^{a}$
}

\begin{abstract}
The standard Hansen measure of accessibility is extended to provide a use-based measure of accessibility reflecting the elasticity of use with respect to the level of provision of facilities. This is further extended to provide a measure of accessibility to linear features, such as trails (as opposed to features at point locations such as parks and libraries). Results from a survey on the use of urban trails in Indianapolis, Indiana are used to test the ability of this accessibility measure to predict trail use. The use-based measure of accessibility to linear features provides better predictions of use and more consistent estimates of the effects of distance and level of facility provision on trail use.
\end{abstract}

Keywords: Accessibility measures, urban trails, transportation modeling, Indianapolis (U.S.A.)

\section{Introduction}

For discretionary use of facilities such as parks, libraries, or urban trails, use can be expected to vary with the level of service provision. Overall service provision includes the number of facilities, their sizes, and other aspects of attractiveness that will affect a person's use. Distances to the facilities will also affect use. The combination of level of service provision and distances determine the accessibility to the facilities, which will be related to use.

Traditional measures of accessibility have limitations in addressing the use of such facilities. Most accessibility measures explicitly address the effect of distance on the level of accessibility and therefore capture the effect of distance on levels of use. But these measures do not explicitly consider the effect that levels of overall facility provision and accessibility have on levels of facility use.

For facilities such as urban trails that have a linear extent, traditional measures of accessibility have another limitation. Most accessibility measures are measures of accessibility to opportunities located at discrete points. While they frequently allow for

ajottensm@iupui.edu

Copyright 2008 John R. Ottensmann and Greg Lindsey.

Licensed under the Creative Commons Attribution - NonCommercial License 3.0. 
measures of variation in the attractiveness of those opportunities, they do not provide for consideration of variation in the spatial extent.

This paper develops a use-based measure of accessibility to linear features intended to address these limitations. The first step extends a standard measure of accessibility to point features to incorporate the effect of level of facility provision on the use of the facilities. This is then further extended to provide for accessibility to linear features. The resulting measure of accessibility is applied to the prediction of the use of urban trails in Indianapolis, Indiana.

\section{Accessibility and Spatial Interaction Models}

A wide variety of measures of accessibility have been proposed and used in different contexts (Handy and Niemeier 1997). Perhaps the most widely used accessibility measure is a generalized form of the measure originally proposed by Hansen (1959). This is the sum over all destinations of the numbers of opportunities or the attractiveness of each destination multiplied by some function of the cost of travel to the destination, $\sum_{j} O_{j} f\left(C_{i j}\right)$. Among the earliest applications of this accessibility measure to the use of facilities was the use of accessibility to population in models for the prediction of the location of retail activity by Huff (1963) and Hansen and Lakshmanan (1965).

Measures of accessibility based upon the original formulation by Hansen continue to be developed and used in a wide range of contexts. In a recent edited volume dealing generally with issues of accessibility (Levinson and Krizek 2005), over half of the chapters used or referred to Hansen accessibility measures. Shen (1998) examined the employment accessibility of low-wage workers in inner-city neighborhoods. He developed a variant of the standard Hansen accessibility measures that incorporates the demand for jobs along with the accessibility to the supply of jobs available at any location and further considers the types of jobs and the mode of travel to the jobs. Willigers, Floor, and van Wee (2007) incorporated a Box-Cox function for the cost function in the Hansen accessibility measure and used this to examine location choices for offices. Wang and Lo (2007) developed a measure of relative Hansen accessibility to examine immigrant grocery-shopping behavior. Guagliardo (2004) reviewed studies of spatial accessibility to primary healthcare, describing the use of Hansen measures of accessibility and extensions to the original formulation. Other examples of applications of Hansen accessibility measures include the prediction of economic development (Ozbay, Ozmen-Ertekin, and Berechman 2003), measuring equity in the accessibility to playgrounds (Talen and Anselin 1998), and the effects of employment accessibility on levels of crime (Wang and Minor 2002; Wang 2007).

The relationship between accessibility and use is formalized within the context of spatial interaction models. The unconstrained and singly constrained spatial interaction models incorporate the standard Hansen measure of accessibility in predicting 
use or allocating use among various destinations (Fotheringham and O'Kelly 1989). In the unconstrained model, predicted spatial interaction is proportional to accessibility, while in the singly constrained model, the predicted total interaction is constrained to equal known numbers of origins (or destinations).

The problem of use depending on the level of opportunities has been addressed in numbers of proposed modifications to the standard spatial interaction models, though these ideas have not been translated back to associated measures of accessibility. Alonso (1978) proposed a system of models of movement in which the unconstrained and singly constrained models were special cases, with the more general cases including partially constrained models that provided for varying levels of interaction with respect to opportunities. This involves effectively placing a variable exponent on accessibility within the spatial interaction model. Further discussions of Alonso's approach and similar "families" of spatial interaction model are provided by Hua (1980), Wilson (1980), and Pooler (1994a, 1994b). Ottensmann (1997) developed partially constrained spatial interaction models and applied them to the use of public libraries.

Fotheringham and Dignan (1984) and Fotheringham and O'Kelly (1989) argue that such "quasi-constrained" gravity models are appropriate when the variables used as measures of origins or destinations (their "site" variables) are inaccurate representations of the actual numbers of origins or destinations. An alternative argument relevant to the current context is that even if the origin measures accurately represent the propensity for interaction at the origins, the level of interactions will depend on the opportunities available at each origin (their "situation" variables). The partially constrained gravity model captures this dependence on opportunities and allows for the elasticity of interaction with respect to the levels of those opportunities.

Several authors have proposed that the problem of interaction quantity depending on opportunities be addressed through the development of combinations of trip distribution (spatial interaction or gravity) models with trip generation models. Wilson (1971), Cesario (1975), McAllister and Klett (1976), and Ewing (1980) have proposed models that are generally equivalent to the partially constrained spatial interaction models proposed by Alonso and others. These models incorporate a trip generation function for the origins which consists of some origin-propensity measure times a function of accessibility to destination opportunities.

The equivalence of the partially constrained model to the combined trip generation and trip distribution model suggests the importance of focusing on the trip generation aspect of the process. Within this context, several authors have attempted to estimate the elasticities of travel with respect to the supply of destination opportunities available. Vickerman (1974) found some effect of the supply of shopping and leisure opportunities on the level of shopping and leisure travel respectively. McAllister and Klett (1976) and Cesario (1975) obtain elasticity values ranging from 0.4 to 0.6 for longer distance recreation trips, while Edwards and Dennis (1976) did not obtain elasticity values that 
were significantly different from zero.

These studies support the idea that levels of use may depend on the levels of destination opportunities available. All of the studies cited that empirically addressed the elasticity of facility use considered (at least) the use of recreation, leisure or library facilities. This emphasizes the importance of consideration of elasticity of use with respect to the level of facility provision for facilities such as parks, libraries, and trails, for which the choice of using the facility is discretionary.

Relatively few studies have explored the relationship between trail use and proximity to trails, and none has considered accessibility as distinct from distance or proximity. Lindsey et al. (2008) show that traffic counts on trails are correlated with neighborhood socio-demographics (including the population densities in areas proximate to the trails), urban form, and the physical characteristics of trail segments. Krizek and Johnson (2006, p. 33) found that "distances to retail and bicycle facilities are statistically significant predictors of choosing active modes of transport at close distances," but their multivariate models also did not include more general measures of accessibility to the facilities. Nelson and Allen (1997) and Dill and Carr (2003) have explored the correlation between rates of bicycle commuting and the provision of on-street bicycle facilities. Some studies of trail use report proportions of users within distance ranges (e.g., Lindsey 1999) or mean or median distance to trails (e.g., Moore et al. 1992). Gobster (1995) illustrated distance decay functions for use of trails in the Chicago region of northeastern Illinois using survey data, but he did not consider the availability of trails or formal measures of accessibility to them.

\section{A Use-Based Measure of Accessibility to Linear Features}

Traditional measures of accessibility have two limitations for the prediction of the use of facilities such as urban trails. First, the use of such facilities would be expected to depend on the overall provision of the facilities in the area. Traditional accessibility measures reflect the effect of distance on the use of the facilities. They do not explicitly incorporate the effect that the level of provision will have on use. Second, traditional measures address accessibility to opportunities at point locations. They do not consider accessibility to features that have a linear extent.

This section develops a use-based measure of accessibility to linear features in two steps. The first part develops a use-based measure of accessibility to opportunities located at points, incorporating the effect of accessibility on the overall level of use made of those opportunities. This measure is then extended to a measure of accessibility to linear features. 


\subsection{A Use-Based Measure of Accessibility to Point Features}

The development begins with the traditional Hansen (1959) measure of accessibility, which remains one of the most widely used measures of accessibility to destinations:

$$
A_{i}=\sum_{j} O_{j} f\left(C_{i j}\right)
$$

where $A_{i}$ is accessibility at location $i, O_{j}$ the number of opportunities at $j$ (or a measure of the attractiveness of the opportunity at $j$ ), and $f\left(C_{i j}\right)$ is a function of the generalized travel cost from $i$ to $j$. (All variables and their definitions are listed in the Appendix.) A negative exponential function of distance (or time) is frequently used for the cost function:

$$
f\left(C_{i j}\right)=\exp \left(-\gamma d_{i j}\right)
$$

where $d_{i j}$ is the distance from location $i$ to destination $j$, and $\gamma$, the accessibility coefficient, is an empirically determined parameter measuring the effect of distance on interaction with the destinations.

For accessibility to opportunities such as parks or libraries, for which use is discretionary, levels of use depend on the overall level of accessibility to the opportunities. This measure of accessibility incorporates the effect of distance on the use of the facilities, but it does not specifically reflect the effect of the overall level of accessibility on overall levels of use.

The relationship between this measure of accessibility and the use of facilities can be seen by considering the role of accessibility in spatial interaction models. The singly constrained spatial interaction model applies the constraint that the total use of all of the facilities by the person or persons at $i$ is fixed and does not depend on opportunities or accessibility. The assumption is that the use of the facilities is totally inelastic with respect to accessibility:

$$
U_{i j}=\kappa P_{i} O_{j} f\left(C_{i j}\right) A_{i}^{-1}
$$

where $U_{i j}$ is the use by persons at $i$ of facilities at $j$ and $P_{i}$ is the number of persons at location $i$ (or some function of the number of persons and their characteristics associated with use of the facilities). The constraint is obtained by multiplying by the inverse of accessibility, causing the total use by persons at $i, \kappa P_{i}$, to be apportioned to the destinations in proportion to each destination's contribution to total accessibility, $O_{j} f\left(C_{i j}\right)$. While this may be reasonable for situations in which total interactions are fixed, as in allocating spending among retail establishments, it does not provide for increases in use with increased accessibility. Total facility use $U_{i}$ by the person or persons at $i$ would then be

$$
U_{i}=\sum_{j} U_{i j}=\kappa P_{i}
$$


Alternatively, in the unconstrained spatial interaction model, the predicted use by persons at origin $i$ using facility $j$ is as follows:

$$
U_{i j}=\kappa P_{i} O_{j} f\left(C_{i j}\right)
$$

This is highly unrealistic, in that the addition of a new facility causes prediction of the use of that facility with no decrease in the predicted use of existing facilities. Total facility use by the persons at $i$ would then be

$$
\begin{aligned}
U_{i} & =\sum_{j} U_{i j} \\
& =\sum_{j} \kappa P_{i} O_{j} f\left(C_{i j}\right) \\
& =\kappa P_{i} A_{i}
\end{aligned}
$$

This implies that total use is proportional to total accessibility. Use is completely elastic with respect to accessibility, which is unreasonable.

An alternative is a model predicting use of facilities relaxing the accessibility-based constraint in the singly constrained model by exponentiating accessibility not to -1 but a value with a magnitude that is allowed to be less than -1 :

$$
U_{i j}=\kappa P_{i} O_{j} f\left(C_{i j}\right) A_{i}^{-(1-\alpha)}
$$

where $0 \leq \alpha \leq 1$. The parameter $\alpha$ can be interpreted as a measure of the elasticity of total use with respect to accessibility. For $\alpha=0$, complete inelasticity, this equation is equivalent to the singly constrained model, while for $\alpha=1$, complete elasticity, the equation is equivalent to the unconstrained model. ${ }^{1}$

Now the total use by persons at $i$ is

$$
\begin{aligned}
U_{i} & =\sum_{j} U_{i j} \\
& =\sum_{j} \kappa P_{i} O_{j} f\left(C_{i j}\right) A_{i}^{-(1-\alpha)} \\
& =\kappa P_{i} A_{i}^{\alpha}
\end{aligned}
$$

Total use is then proportional to $A_{i}^{\alpha}$, the standard Hansen accessibility $A_{i}$ raised to some power less than or equal to 1 . For values of $\alpha$ greater than 0 and less than 1 ,

\footnotetext{
${ }^{1}$ While the development of this accessibility measure proceeds in a slightly different manner, it is equivalent to the multiplicative model presented in Ottensmann (1997).
} 
use would increase with $A_{i}$ but not as rapidly as $A_{i}$ is increasing. This forms the basis for defining use-based accessibility $A_{i}^{*}$ as

$$
A_{i}^{*}=A_{i}^{\alpha}=\left\{\sum_{j} O_{j} f\left(C_{i j}\right)\right\}^{\alpha}
$$

where $\alpha$ has the value that results in the best prediction of use. Predicted use would then be proportional to this use-based measure of accessibility. The value of the parameter $\alpha$ is the measure of elasticity given the configuration of facilities producing the current $A_{i}$ values associated with the measured use of the facilities. Elasticity might be expected to vary with levels of facility provision producing different accessibilities, much as price or income elasticities, for example, might vary for different price or income levels.

This is a use-based measure of accessibility to point features such as parks or libraries that incorporates both the effect of distance on use, via the cost function and the accessibility coefficient(s) in the cost function, and the effect of the overall level of accessibility on use, measured by the elasticity coefficient, $\alpha$.

\subsection{Use-Based Measure of Accessibility to Linear Features}

The original Hansen measure of accessibility and this use-based measure of accessibility measure the accessibility to destinations located at specific points. However destinations can be linear features, such as urban trails, as opposed to point locations. People use multiple points along a trail. So it is appropriate to develop a measure of accessibility to such linear destinations.

Assume multiple linear features such as trails, $j=1, \ldots, n$. For each trail $j$, the cost function between location $i$ and the trail will vary as a function of distance along the trail, $f\left(C_{i j}(s)\right)$, where $s$ is distance along the trail from the start to the end at trail length $L_{j}$. The opportunities (measures of attractiveness) may likewise vary with distance along the trail, giving the function $O_{j}(s)$, though attractiveness could also be assumed constant along the entire trail. The measure of use-based accessibility $A^{* L}$ would be

$$
A_{i}^{* L}=\left\{\sum_{j}\left[\int_{0}^{L j} O_{j}(s) f\left(C_{i j}(s)\right) d s\right]\right\}^{\alpha}
$$

integrating over distance along the trail on the opportunity and cost functions along each trail. In practice, one would develop a numerical solution to the integration by summing over segments along the trails, which could either be segments of equal or arbitrary length:

$$
A_{i}^{* L}=\left\{\sum_{j}\left[\sum_{k} L_{j k} O_{j k} f\left(C_{i j k}\right)\right]\right\}^{\alpha}
$$


where $L_{j k}$ is the length of segment $k$ on trail $j, O_{j k}$ is the attractiveness of that segment, and $f\left(C_{i j k}\right)$ is the function of cost from location $i$ to segment $k$ on trail $j$. Again, $\alpha$ is a measure of elasticity of use with respect to the level of accessibility, selected such that the measure of use-based accessibility best predicts trail use.

This use-based measure of accessibility to linear features provides a number of advantages over simpler measures of accessibility. By treating the destinations as linear features, accessibility to the entire extent of the feature is considered, as opposed to a simpler measure of accessibility to a single point along the feature. In addition, incorporating the linear extent of the features allows inclusion of varying levels of attractiveness that may be associated with different sections of each feature. And this is a use-based measure of accessibility that separates the effects the elasticity of use with respect to overall accessibility from the effects of distance on use.

\section{Data and Methods}

This study examines the application of the use-based measure of accessibility to linear features to the use of the urban trail (greenway) system in Indianapolis, Indiana. This section describes the trail system, the survey of the use of the trails, and the models and methods that are used.

\subsection{Urban Trail System in Indianapolis}

Beginning in the 1990s, Indianapolis undertook the development of an extensive system of urban trails or greenways. The longest, best-known, and most-used of these is the Monon Trail, built on an abandoned railway corridor and extending from the central business district north to the city/county boundary (and now, beyond, into the adjoining county). Other trails have been developed along various rivers and canals. The system currently includes about 54 kilometers (over 33 miles) of trails, with the majority located in the central and northern parts of the city.

The Center for Urban Policy and the Environment began to study the use of the trails in 2001. Ultimately 30 monitoring stations recording the passage of persons along the trails using infrared counters have been established. ${ }^{2}$ The trails have been divided into segments associated with each of these monitoring locations. These trail segments are used in this paper to compute the measures of linear accessibility, with the monitoring station locations being used as the points to which distances to those

\footnotetext{
${ }^{2}$ One very short trail, Pogue's Run, has not had a monitoring station established along the trail. For purposes of this analysis, the entire trail is treated as a single segment, with the point for the calculation of distance being placed at the midpoint of this trail.
} 
segments are measured. ${ }^{3}$ Figure 1 shows the extent of the trails and the monitoring locations.

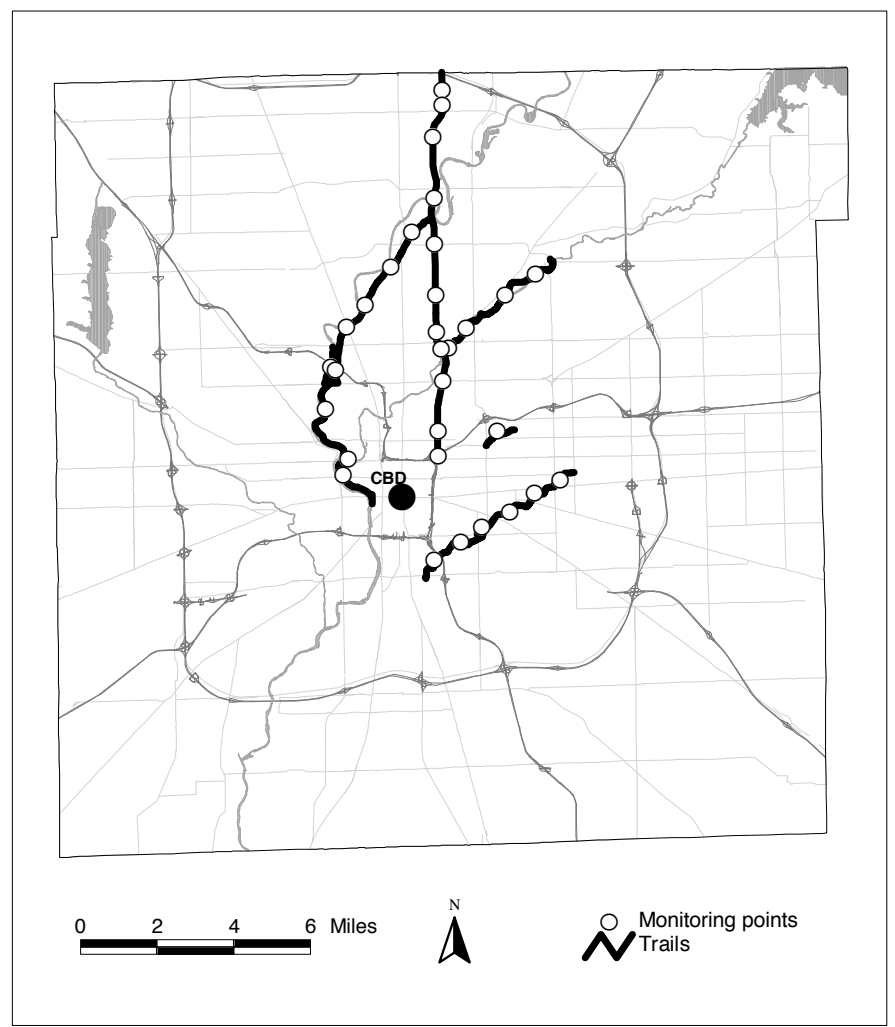

Figure 1: Trails and monitoring points in Indianapolis, Marion County, Indiana

\subsection{Survey of Trail Use}

This study uses data on the use of the trails from the Marion County Health \& Hospital Corporation Obesity Survey (MCOS) conducted in 2006. The survey involved a random sample of 4,780 adults from throughout Marion County (Indianapolis). The

\footnotetext{
${ }^{3}$ The Monon Trail continues north from the city-county boundary into the adjoining county. Calculation of accessibilities to this trail could be improved by including the extent of the trail outside of Indianapolis. But since the focus of the study was Indianapolis and because data on the trail outside of Indianapolis were not available, the measures of accessibility are restricted to the extent of that trail within Indianapolis. This has the effect of somewhat underestimating trail accessibility in the northernmost sections of the city.
} 
survey design included an oversampling of African-Americans and Hispanics, with further oversampling of males from those groups to provide sufficient cases for the analysis of issues relating to obesity for these groups. All analyses are appropriately weighted to reflect the probabilities of members of various groups being included in the sample.

Survey respondents were asked to provide the cross streets for the intersection nearest their residence. This information was geocoded to provide the approximate locations of the respondents' residences. ${ }^{4}$ Distances from the respondents' residences to the monitoring locations were determined by finding the shortest-path network distances using the street network for Marion County.

With respect to the use of the trails, the survey included questions on whether the respondent had used each of the six trails in the Indianapolis trail system within the previous month. For this study, these are combined into a single measure of whether any of the trails were used. The map in Figure 2 shows the locations of the survey respondents, indicating which have answered that they have used one or more of these trails in the previous month. As would be expected, the trail users tend to be concentrated in areas closer to the trails. The survey also asked the respondents the number of times they have used trails in the previous month. ${ }^{5}$

Trail users could be using the trails for recreational purposes or for transportation, such as travel to work. For the latter purposes, trail accessibility to potential destinations could also play a significant role in affecting trail use along with accessibility from potential users' residences. Unfortunately, the survey provides no information on whether trail use was for recreation or transportation and no information about destinations for transportation use. Therefore, this study focuses on the accessibility to

\footnotetext{
${ }^{4}$ Examination of a map of the geocoded locations suggests that many respondents provided intersections with major thoroughfares rather than the nearest intersection. This would introduce some additional error into the information on residence locations, but error that might be expected to be randomly distributed.

5 The survey asked whether the respondents had used any recreational trail in the past month, whether they had used any of the six greenway trails, and whether they had used any other trails (and which ones). Respondents reported using other trails within parks in Indianapolis and trails outside of Indianapolis. (One respondent reported using the Appalachian Trail.) The question on the number of times trails were used in the previous month was not restricted to the six trails in the greenway system, so the response would include the use of those other trails. For this analysis, which focuses on the use of the greenway trail system, counts of the number of times trails were used were included only for those respondents indicating on the prior questions that they had used one of the greenway trails. This can lead to an overcount of the number of times those respondents had used the greenway trails, as some may also have used other trails and have included that use in their counts. Of the 3,376 respondents who did not use the greenway trails, only 109 reported using other trails. Of those 109, 85 reported using the other trails 5 or fewer times, which is less than the mean number of trail uses reported by those respondents reporting using the greenway trails. Looked at another way, the mean number of times trails were used by those using the greenways was 5.8, while the mean number of times trails were used by those not using the greenways was 0.16 . So the use of other trails by those reporting use of the greenways is not expected to have a major effect in inflating their reported trail use.
} 


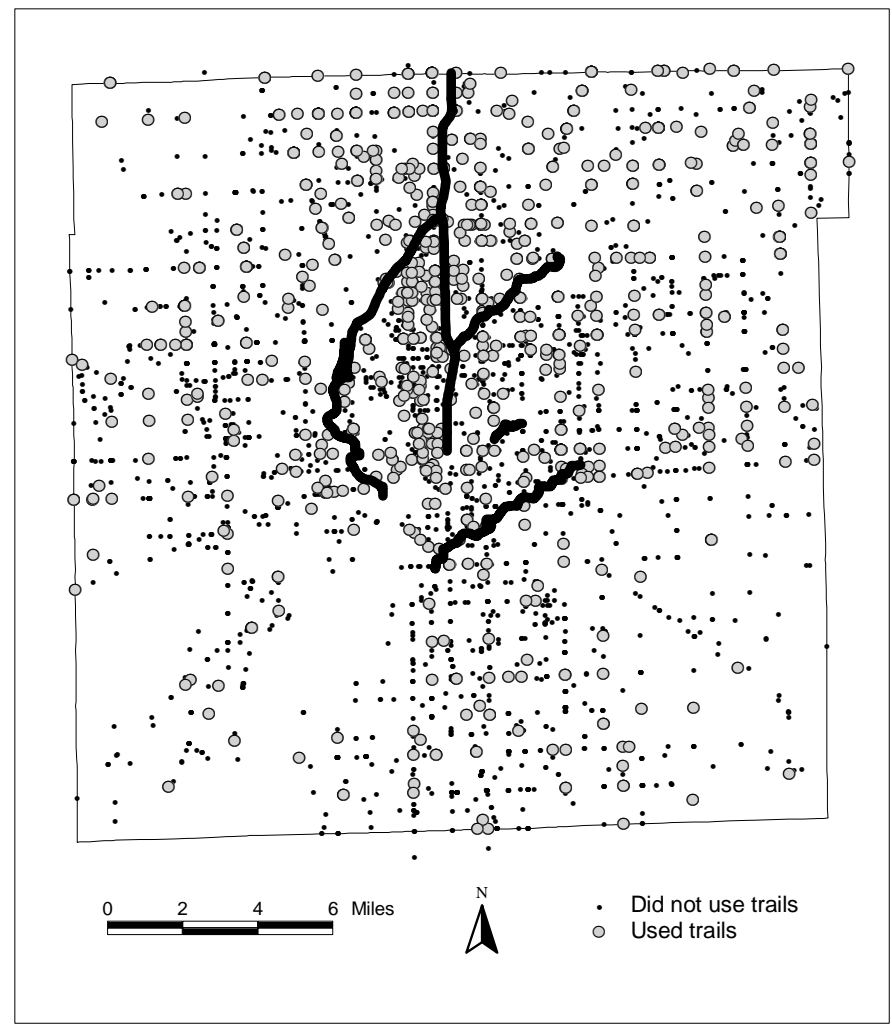

Figure 2: Trails and trail users

the trails at the respondents' residences.

The survey also included questions about various respondent characteristics, including gender, race, Hispanic status, age, education, and household income, all of which are associated with the use of the trails. Table 1 presents descriptive statistics for the respondent characteristics, distance to the nearest trail, and the number of times the respondents reported using trails, broken down by whether the respondent reported use of any of the trails. For this table and the subsequent analyses, cases missing data on any of these variables have been excluded, reducing the final sample size from 4,780 to 4,129 . (A large majority of the missing cases involved failure to answer the questions on household income.)

Just over twenty percent of the respondents reported using at least one of the trails in the preceding month. Males were more likely to use the trails than females. AfricanAmericans were less likely and whites more likely to use the trails, but those differences 
were small. However, the proportion of Hispanics using the trails was just over half the proportion not using the trails. Persons using the trails were more likely to be under age 65, to be college graduates, and to have incomes greater than 300 percent of the federal poverty level. ${ }^{6}$ The mean network distance to the nearest trail was 4.8 kilometers $(2.9$ miles) for trail users and 7.0 kilometers $(4.4$ miles) for those not using the trails. Trail users reported using trails an average of 5.8 times during the previous month.

Table 1: Descriptive Statistics

\begin{tabular}{lccc}
\hline Variable & Used trail & Did not use trail & Total \\
\hline Proportion male & 0.550 & 0.469 & 0.486 \\
Proportion African-American & 0.216 & 0.231 & 0.228 \\
Proportion non-Hispanic white & 0.730 & 0.702 & 0.708 \\
Proportion Hispanic & 0.023 & 0.043 & 0.039 \\
Mean age & 39.7 & 46.0 & 44.7 \\
Proportion age less than 65 & 0.960 & 0.843 & 0.867 \\
Proportion college graduate & 0.595 & 0.325 & 0.381 \\
Proportion income greater than 300\% & 0.754 & 0.593 & 0.626 \\
poverty level & & & \\
Mean distance to nearest trail (km) & 4.81 & 7.02 & 6.56 \\
Number of times using trail in past & 5.81 & 0.00 & 1.21 \\
month & & & \\
\hline$N$ & 857 & 3,272 & 4,129 \\
Proportion using trail & -- & -- & 0.208 \\
\hline
\end{tabular}

\subsection{Models Using Accessibility to Predict Trail Use}

The models to be estimated predict trail use using the respondent characteristics and the use-based measure of accessibility to linear features:

$$
\begin{aligned}
T_{i} & =\beta_{0}+\beta_{\mathbf{R}} \mathbf{R}_{i}+\beta_{a} A_{i}^{* L} \\
& =\beta_{0}+\beta_{\mathbf{R}} \mathbf{R}_{i}+\beta_{a}\left\{\sum_{j}\left[\sum_{k} L_{j k} O_{j k} \exp \left(-\gamma d_{i j k}\right)\right]\right\}^{\alpha}
\end{aligned}
$$

\footnotetext{
${ }^{6}$ The survey obtained income in relation to various multiples of the federal poverty level, which depends on the number of persons in the household. Questions were asked whether incomes were above or below income thresholds that were determined based upon prior responses on the number of persons living in the household. Therefore, no information is available on absolute income levels as opposed to the poverty levels incorporating household size.
} 
where $T_{i}$ is the trail use by respondent $i, \mathbf{R}_{i}$ is a vector of respondent characteristics for respondent $i$, and $A_{i}^{* L}$ is the use-based linear accessibility for respondent $i$. The $\beta_{0}, \beta_{\mathbf{R}}$, and $\beta_{a}$ are the corresponding regression coefficients, $\gamma$ is the accessibility coefficient in the negative exponential cost function of distance, and $\alpha$ is the elasticity coefficient in the use-based measure of accessibility.

The measures of trail use are whether the respondent used any of the trails in the previous month and the number of times the respondent reported using trails during that period. Models using the first measure, whether or not the respondent used a trail, were estimated using logistic regression. The second measure, the count of the number of times the respondent used the trail, provides greater information on the use made of the trails. As is often the case with count data, the distribution is not normal, with declining frequencies for higher counts. This suggests a Poisson distribution and the use of Poisson regression. Tests using Poisson regression found overdispersion, making negative binomial regression the appropriate choice for estimating the models predicting the frequency of trail use.

The measures of trail use reflect the respondents' use of any of the trails in the system, not the use of specific trails. This is appropriate given that the measure of accessibility being considered is a measure of accessibility to the entire system of trails, not to individual trails. The use made of any individual trail will depend on the presence of the other trails as alternatives. Given information on the frequency of use made of each individual trail (or even better, each trail segment), it would be possible to incorporate the measure of accessibility into a spatial interaction model predicting the use of the individual trails or segments. The data available from the survey do not support such disaggregation.

Because certain groups were oversampled in the survey, the models are estimated weighting by the inverse of the probability of respondents in the various strata being included in the sample. Given this weighting, the normal standard errors would be underestimates of the variation in the regression coefficients. Therefore, robust standard errors calculated using the Huber-White sandwich estimator of the variance are reported (Stata User's Guide 2005, pp. 275-280, 285-286).

The complexity of the functional form of the measure of accessibility means that the values of the accessibility coefficient, $\gamma$, and the elasticity coefficient, $\alpha$, cannot be directly estimated in the regressions. An iterative, trial-and-error procedure was employed to determine the estimates for these coefficients that resulted in the best fit of the models, maximizing the log likelihood values.

The procedure used is illustrated in Figure 3 and proceeded as follows: A set of accessibility measures using a range of accessibility coefficients, $\gamma$, (with the elasticity coefficient, $\alpha$, originally set to 1 ) are calculated using an external program and are brought into the statistical analysis dataset. The model is estimated using different accessibilities reflecting different accessibility coefficients to determine the accessibility 
coefficient that results in the best fit of the model as measured by the maximum value for the $\log$ likelihood. Then a new set of accessibility measures is created using the

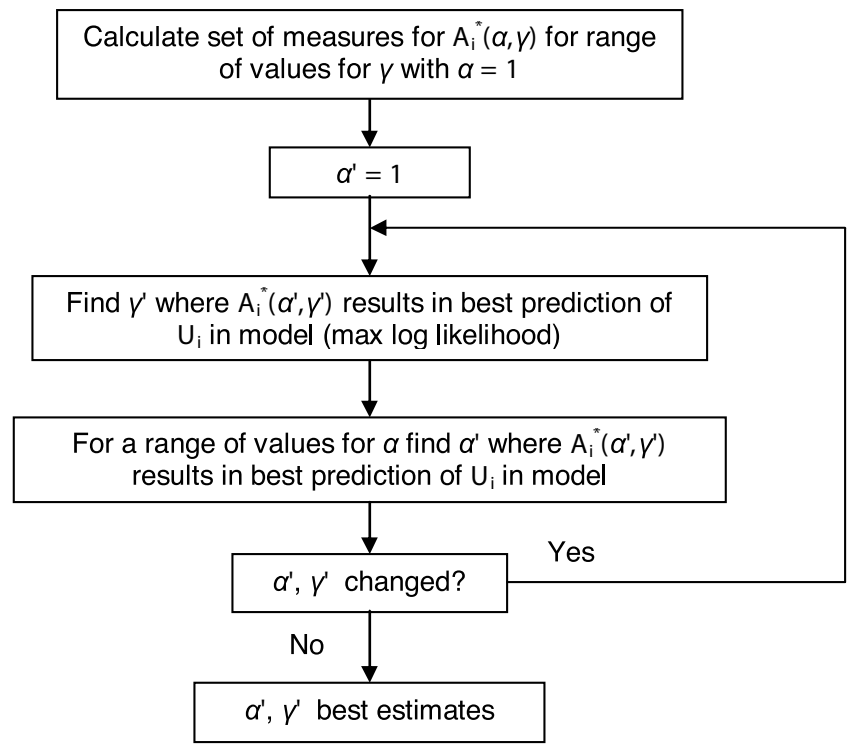

Figure 3: Iterative estimation of $\alpha$ and $\gamma$ parameters

accessibility variable with best fit accessibility coefficient and a range of elasticity coefficients (raising the original accessibility to those powers). Once again, the model is estimated using these accessibilities with the various elasticities to find the value for the elasticity coefficient resulting in the best fit. This elasticity coefficient is then applied to the original set of accessibilities for a range of accessibility coefficients and these are tested to find the best accessibility coefficient using that elasticity coefficient. The process is repeated, back and forth, first searching over the accessibility coefficient and then over the elasticity coefficient until a solution is found in which further adjustment of either coefficient produces no improvement in the fit of the model as measured by the log likelihood. The process is carried out to estimate the values for the accessibility coefficient and the elasticity coefficient to two significant digits. Changes in the coefficients in the second significant digit result in changes no greater than in the sixth significant digit of the log likelihood.

\section{Accessibility Model Results}

The application of the use-based linear accessibility measure for predicting trail use in Indianapolis is examined using two sets of models, logistic models predicting whether 
persons used a trail and negative binomial models predicting the number of times they used trails.

\subsection{Logistic Models Predicting Trail Use}

The first set of models consider whether or not the survey respondents reported using any of the six trails in the Indianapolis greenway system during the previous month. The models are estimated using logistic regression.

The first model reported in Table 2 uses only respondent characteristics to predict the probability that a person will use any of the trails. Males, persons less than 65 years old, college graduates, and members of households with incomes greater than 300 percent of the poverty level are more likely to make use of the trails. Hispanics are less likely to use the trails. The model as a whole and each of the regression coefficients are all statistically significant, and all but the regression coefficient for Hispanic are significant at the 0.01 level.

The subsequent models examine the effect of adding measures of accessibility to the trails to the respondent characteristics for predicting the probability of trail use. The second regression uses simple network distance to the nearest monitoring location on the trail system. As expected, the probability of using a trail declines with distance, with the odds ratio less than 1 . The regression coefficient for distance is significant at the 0.01 level. Adding distance improves the fit of the model, and the pseudo- $R^{2}$ increased from 0.074 to 0.129 .

The measure of linear accessibility to the trail system is included in the third model but without providing for the use-based form; the elasticity coefficient $\alpha$ is fixed at 1. The value for the best-fit accessibility coefficient is estimated as described above, resulting in an accessibility coefficient $\gamma$ of 0.45 . The probability of trail use increases with the accessibility measure and the regression coefficient is statistically significant. The fit of the model is greater than the model using simple distance to the nearest trail as indicated by the Akaike information criterion. (The reported AIC values for the regressions using accessibilities have been adjusted for the additional parameters estimated for the accessibility measures.)

The final model incorporates the full measure of use-based linear accessibility, providing for the adjustment of both the accessibility and elasticity coefficients. The value of the accessibility coefficient $\gamma$ estimated for this model is higher than for the previous model, 0.63 . The elasticity coefficient $\alpha$ has an estimated value of 0.47 , indicating a significant level of elasticity in trail use with respect to accessibility to the trails. The odds ratio for this measure of accessibility is over twice the value for the previous measure of accessibility that did not include the elasticity coefficient. The fit of the model is the best of all four of the models presented using the Akaike information criterion.

With the final two models incorporating the measures of accessibility to the trails, 
Table 2: Logistic regression models for use of trails (odds ratios; robust standard errors in parentheses)

\begin{tabular}{|c|c|c|c|c|}
\hline $\begin{array}{l}\text { Independent } \\
\text { variables }\end{array}$ & $\begin{array}{l}\text { Respondent } \\
\text { characteristics } \\
\text { only }\end{array}$ & $\begin{array}{l}\text { Distance to } \\
\text { nearest trail }\end{array}$ & $\begin{array}{l}\text { Linear } \\
\text { accessibility, } \\
\text { no elasticity } \\
\text { coefficient }\end{array}$ & $\begin{array}{l}\text { Linear } \\
\text { accessibility, } \\
\text { elasticity } \\
\text { coefficient }\end{array}$ \\
\hline Male & $\begin{array}{l}1.30^{* *} \\
(0.12)\end{array}$ & $\begin{array}{l}1.22^{*} \\
(0.11)\end{array}$ & $\begin{array}{l}1.19 \\
(0.11)\end{array}$ & $\begin{array}{l}1.19 \\
(0.11)\end{array}$ \\
\hline Hispanic & $\begin{array}{l}0.64^{*} \\
(0.12)\end{array}$ & $\begin{array}{l}0.67^{*} \\
(0.13)\end{array}$ & $\begin{array}{l}0.77 \\
(0.15)\end{array}$ & $\begin{array}{l}0.74 \\
(0.15)\end{array}$ \\
\hline $\begin{array}{l}\text { Age less than } 65 \\
\text { years }\end{array}$ & $\begin{array}{l}3.98^{* *} \\
(0.64)\end{array}$ & $\begin{array}{l}4.56^{* *} \\
(0.75)\end{array}$ & $\begin{array}{l}4.43^{* *} \\
(0.76)\end{array}$ & $\begin{array}{l}4.52^{* *} \\
(0.75)\end{array}$ \\
\hline College graduate & $\begin{array}{l}2.60^{* *} \\
(0.25)\end{array}$ & $\begin{array}{l}2.61^{* *} \\
(0.26)\end{array}$ & $\begin{array}{l}2.50^{* *} \\
(0.25)\end{array}$ & $\begin{array}{l}2.53^{* *} \\
(0.25)\end{array}$ \\
\hline $\begin{array}{l}\text { Income }>300 \% \\
\text { poverty level }\end{array}$ & $\begin{array}{l}1.36^{* *} \\
(0.15)\end{array}$ & $\begin{array}{l}1.65^{* *} \\
(0.18)\end{array}$ & $\begin{array}{l}1.73^{* *} \\
(0.20)\end{array}$ & $\begin{array}{l}1.74^{* *} \\
(0.20)\end{array}$ \\
\hline $\begin{array}{l}\text { Distance to nearest } \\
\text { trail }(\mathrm{km})\end{array}$ & -- & $\begin{array}{l}0.86^{* *} \\
(0.01)\end{array}$ & -- & -- \\
\hline $\begin{array}{l}\text { Accessibility, } \\
\gamma=0.45, \alpha=1.0\end{array}$ & -- & -- & $\begin{array}{l}1.38^{* *} \\
(0.035)\end{array}$ & -- \\
\hline $\begin{array}{l}\text { Accessibility, } \\
\gamma=0.63, \alpha=0.47\end{array}$ & -- & -- & -- & $\begin{array}{l}3.02^{* *} \\
(0.023)\end{array}$ \\
\hline$N$ & 4129 & 4129 & 4129 & 4129 \\
\hline Wald $\chi^{2}$ & $242.67^{* *}$ & $346.87^{* *}$ & $386.82^{* *}$ & $388.57^{* *}$ \\
\hline Pseudo- $R^{2}$ & 0.0743 & 0.1294 & 0.1388 & 0.1417 \\
\hline Log likelihood & -1952.48 & -1836.27 & -1816.40 & -1810.24 \\
\hline $\begin{array}{l}\text { Akaike information } \\
\text { criterion }\end{array}$ & 3916.96 & 3686.54 & 3648.80 & 3638.49 \\
\hline
\end{tabular}

${ }^{*} \mathrm{p}<0.05,{ }^{* *} \mathrm{p}<0.01$ 
the estimated odds ratios for males and Hispanics are no longer statistically significant as they were in the first two models. The odds ratios for males and Hispanics for the latter models are slightly closer to one, indicating smaller effects. The changes are not great, so too much should not be read into this. However, it may be that given the locations of the respondents, when trail accessibility is more accurately incorporated into the model, differences by gender and Hispanic status become less important in determining differences in trail use.

The pseudo- $R^{2}$ values are quite low, indicating that the models explain only a small portion of the variation in trail use (though the pseudo- $R^{2}$ did nearly double from the first model without distance or accessibility to the final model incorporating the full linear accessibility measure). Obviously many other factors contribute to the decision to use a trail, ranging from characteristics of the individual and the individual's neighborhood to variations in the trail segments and the areas adjacent to those trail segments. In addition, simple questions regarding whether a trail was used in the previous 30 days cannot capture the full range of variation in trail use across the respondents.

In addition to the four models presented in Table 2, models were estimated using point measures of accessibility calculated using distances to the nearest points on each of the trails. The results were similar to those reported using linear accessibility, but the fit of the models were not as good. The estimated coefficients were similar to those obtained for the models using the linear accessibility measures.

\subsection{Negative Binomial Models Predicting Frequency of Trail Use}

The second set of models address the number of times that the survey respondents reported using trails in the previous month. The models have been estimated using negative binomial regression.

In the model using only respondent characteristics to predict the frequency of trail use, this time five of the six predictors were statistically significant as shown in Table 3. Household income greater than 300 percent of the poverty level was not significant in this or any of the subsequent models, suggesting that while it was important in predicting whether the respondents used the trails, the other variables in the model are more important in determining the frequency of trail use. The model as a whole is statistically significant at the 0.01 level.

Following the same pattern as above, the second model includes distance to the nearest monitoring location on the trail system as a simple measure of accessibility. It is statistically significant. The fit of the model as measured by the Akaike information criterion is better than the model using only respondent characteristics.

The third model includes the measure of linear accessibility without the adjustment of the elasticity coefficient $\alpha$, which is kept at 1 . For this model, the value for the best- 
Table 3: Negative binomial regression models for use of trails (robust standard errors in parentheses)

\begin{tabular}{|c|c|c|c|c|}
\hline $\begin{array}{l}\text { Independent } \\
\text { variables }\end{array}$ & $\begin{array}{l}\text { Respondent } \\
\text { characteristics } \\
\text { only }\end{array}$ & $\begin{array}{l}\text { Distance to } \\
\text { nearest trail }\end{array}$ & $\begin{array}{l}\text { Linear } \\
\text { accessibility, } \\
\text { no elasticity } \\
\text { coefficient }\end{array}$ & $\begin{array}{l}\text { Linear } \\
\text { accessibility, } \\
\text { elasticity } \\
\text { coefficient }\end{array}$ \\
\hline Male & $\begin{array}{l}0.42^{*} \\
(0.17)\end{array}$ & $\begin{array}{l}0.32 \\
(0.17)\end{array}$ & $\begin{array}{l}0.23 \\
(0.17)\end{array}$ & $\begin{array}{l}0.23 \\
(0.16)\end{array}$ \\
\hline Hispanic & $\begin{array}{l}-1.14^{* *} \\
(0.27)\end{array}$ & $\begin{array}{l}-0.99^{* *} \\
(0.27)\end{array}$ & $\begin{array}{l}-0.73^{* *} \\
(0.28)\end{array}$ & $\begin{array}{l}-0.75^{* *} \\
(0.27)\end{array}$ \\
\hline $\begin{array}{l}\text { Age less than } 65 \\
\text { years }\end{array}$ & $\begin{array}{l}1.39^{* *} \\
(0.26)\end{array}$ & $\begin{array}{l}1.49^{* *} \\
(0.24)\end{array}$ & $\begin{array}{l}1.46^{* *} \\
(0.24)\end{array}$ & $\begin{array}{l}1.49^{* *} \\
(0.24)\end{array}$ \\
\hline College graduate & $\begin{array}{l}0.93^{* *} \\
(0.16)\end{array}$ & $\begin{array}{l}0.82^{* *} \\
(0.18)\end{array}$ & $\begin{array}{l}0.71^{* *} \\
(0.18)\end{array}$ & $\begin{array}{l}0.72^{* *} \\
(0.18)\end{array}$ \\
\hline $\begin{array}{l}\text { Income }>300 \% \\
\text { poverty level }\end{array}$ & $\begin{array}{l}0.15 \\
(0.21)\end{array}$ & $\begin{array}{l}0.28 \\
(0.22)\end{array}$ & $\begin{array}{l}0.36 \\
(0.20)\end{array}$ & $\begin{array}{l}0.37 \\
(0.20)\end{array}$ \\
\hline $\begin{array}{l}\text { Distance to nearest } \\
\text { trail }(\mathrm{km})\end{array}$ & - & $\begin{array}{l}-0.14^{* *} \\
(0.02)\end{array}$ & - & - \\
\hline $\begin{array}{l}\text { Accessibility, } \\
\gamma=0.48, \alpha=1.0\end{array}$ & - & - & $\begin{array}{l}0.39^{* *} \\
(0.01)\end{array}$ & - \\
\hline $\begin{array}{l}\text { Accessibility, } \\
\gamma=0.62, \alpha=0.54\end{array}$ & - & - & - & $\begin{array}{l}1.03^{* *} \\
(0.11)\end{array}$ \\
\hline Constant & $\begin{array}{l}-1.88^{* *} \\
(0.24)\end{array}$ & $\begin{array}{l}-1.23^{* *} \\
(0.25)\end{array}$ & $\begin{array}{l}-2.69^{* *} \\
(0.30)\end{array}$ & $\begin{array}{l}-2.87^{* *} \\
(0.28)\end{array}$ \\
\hline$N$ & 4129 & 4129 & 4129 & 4129 \\
\hline Wald $\chi^{2}$ & $155.51^{* *}$ & $169.96^{* *}$ & $198.45^{* *}$ & $199.96^{* *}$ \\
\hline Log likelihood & -4130.42 & -4061.33 & -4041.59 & -4038.11 \\
\hline $\begin{array}{l}\text { Akaike information } \\
\text { criterion }\end{array}$ & 8274.84 & 8138.66 & 8101.19 & 8096.23 \\
\hline
\end{tabular}


fit accessibility coefficient $\gamma$ was estimated to be 0.48 . The accessibility measure is statistically significant in the model, which has a better fit than the previous model using distance.

The final model uses the use-based measure of linear accessibility allowing both the accessibility coefficient $\alpha$ and the elasticity coefficient $\gamma$ to be adjusted to find the values resulting in the best fit of the model. The estimated accessibility coefficient is 0.62 and the elasticity coefficient is 0.54 . These coefficients are very similar to the accessibility and elasticity coefficients estimated for the logistic model, which were 0.63 and 0.47 respectively. Using the use-based measure of linear accessibility therefore produces consistent results across the models predicting whether a trail was used and the frequency of use of the trails. This final model had the best fit of all of the models presented in Table 3 as indicated by the Akaike information criterion.

As with the logistic models predicting whether the respondents used the trails, the effects of gender and Hispanic status declined when accessibility is included in the prediction of the frequency of trail use. The male variable again is no longer statistically significant, though the Hispanic variables does retain significance.

Once again, models were also estimated using point measures of accessibility calculated using distances to the nearest points on each of the trails. The fit of the models were not as good as for the models using linear accessibility and the estimated accessibility coefficient for the final model was lower than for the linear accessibility.

\section{Conclusions}

The use-based measure of accessibility to linear features was a highly statistically significant predictor of both the use of trails and the frequency of use. The models using this measure had better fit than alternative models using distance, linear accessibility without the elasticity adjustment for use, and the point-based measures of accessibility to the nearest points on the trail system.

Employing the use-based measure of accessibility to linear features resulted in consistent estimates of the accessibility and elasticity coefficients across the logistic and negative binomial models predicting use of trails and frequency of use. Models using accessibilities to the nearest points on the trails as opposed to accessibilities to the trails as linear features produced varying estimates of the accessibility coefficients.

The measures of use-based accessibility to linear features used here assumed that all trail segments were equally attractive to trail users. Only the lengths of the trail segments were included in the calculation of the accessibility measure. But the form of this accessibility measure provides for the inclusion of measures of differential attractiveness for the trail segments that would be multiplied by the segment lengths. For example, measures of greenness or tree canopy that may increase attractiveness and trail use could be included in the accessibility measure to better measure the attractiveness 
of the trails. Likewise, disamenities such as levels of crime that might discourage trail use could also be incorporated into accessibility.

The use-based measure of accessibility and the models to predict trail use can be used to predict levels of trail use that would be associated with the expansion of the trails or the development of new trails. One could determine the accessibility values associated with current and proposed trail systems for the centroids of census tracts or block groups. Using the characteristics of the population in each area, the probabilities of trail use and the frequencies of trail use could be predicted for various population groups and then multiplied by the groups' populations to produce predictions of total trail use. Comparing the predictions made using accessibilities for the existing trail system and any proposed expansions would provide estimates of the additional use associated with the proposed expansions. These values could be used in assessing the value of possible new trail developments and in comparing alternative proposals to determine which produced the greatest increase in predicted use.

The accessibility measures could also be employed in examining the equity in the provision of trails. Accessibility values calculated for different areas could be used to identify areas and population groups residing in those areas that were underserved by the trail system as indicated by lower levels of accessibility. Changes in the equity of the distribution of trail accessibility could be examined for proposed improvements. Such use of accessibility measures to assess the equity of the distribution of public facilities have been carried out for playgrounds by Talen and Anselin (1998) and for public libraries by Ottensmann (1994).

The most important feature of the use-based measure of accessibility is the explicit inclusion of the measure of elasticity of use with respect to the overall level of provision of opportunities. Doing so provides for the analytical separation of the effect of the level of opportunities on use from the effect of distance (or other measures of cost of interaction). It allows for the separate estimation of those two factors, rather than confounding them in the accessibility parameters that should be estimating the effect of distance alone. This will be of particular importance in the use of accessibility for forecasting the expected use of facilities anticipating the planned addition of new facilities that increase overall levels of accessibility. This benefit is not limited to the measure of accessibility to linear features. The initial use-based measure of accessibility to point features provides this for point destinations such as parks and libraries.

\section{References}

(2005). Stata User's Guide: Release 9. Stata Press, College Station, TX.

Alonso, W. (1978). A theory of movements. In: N. Hansen, ed., Human Settlement Systems, pp. 197-211. Ballinger, Cambridge, MA. 
Cesario, F. (1975). A combined trip generation and distribution model. Transport. Sci., 9: 211-223.

Dill, J. and T. Carr (2003). Bicycle commuting facilities in major U.S. cities: If you build them, commuters will use them-another look. Transport. Res. Rec., 1828: 116-123.

Edwards, S. and S. Dennis (1976). Long distance day tripping in Great Britain. J. Transp. Econ. Policy, 10: 237-256.

Ewing, G. (1980). Progress and problems in the development of recreational trip generation and trip distribution models. Leisure Sci., 3: 1-24.

Fotheringham, A. and T. Dignan (1984). Further contributions to a general theory of movement. Ann. Assoc. Am. Geogr., 74: 620-633.

Fotheringham, A. and M. O'Kelly (1989). Spatial Interaction Models: Formulations and Applications. Kluwer, Boston.

Gobster, P. (1996). Perception and use of a metropolitan greenway system for recreation. Landscape Urban Plan., 33: 401-413.

Guagliardo, M. (2004). Spatial accessibility of primary care: Concepts, methods, and challenges. Int. J. Health Geographics, 3.

Handy, S. and D. Niemeier (1997). Measuring accessibility: An exploration of issues and alternatives. Environ. Planning A, 29: 1175-1194.

Hansen, W. (1959). How accessibility shapes land use. J. Amer. Inst. Planners, 25: 73-76.

Hansen, W. and T. Lakshmanan (1965). A retail market potential model. J. Amer. Inst. Planners, 31: 131-143.

Hua, C. (1980). An exploration of the nature and rationale of a systemic model. Environ. Plann. A, 12: 713-726.

Huff, D. (1963). A probabilistic analysis of shopping trade areas. Land Econ., 39: 81-90.

Krizek, K. and P. Johnson (2006). Proximity to trails and retail: Effects on urban cycling and walking. J. Am. Plann. Assoc., 72: 33-42.

Levinson, D. and K. Krizek, eds. (2005). Access to Destinations. Elsevier, Amsterdam.

Lindsey, G. (1999). Use of urban greenways: Insights from Indianapolis. Landscape Urban Plan., 45: 145-157.

Lindsey, G., J. Wilson, E. Rubchinskaya, J. Yang, and C. Alexa (2008). Urban form, trail characteristics, and trail use: Implications for design. J. Urban Design, 13: 107-132.

McAllister, D. and F. Klett (1976). A modified gravity model of regional recreation activity with an application to ski trips. J. Leisure Res., 8: 21-34.

Moore, R., A. Graefe, R. Gitelson, and E. Porter (1992). The impacts of rail-trails: A study of the users and property owners from three trails. Downloaded from http://www.nps.gov/ncrc/portals/trails/rtcimpact/impact_railtrail_final.pdf. 
Nelson, A. and D. Allen (1997). If you build them, commuters will use them. Transport. Res. Rec., 1578: 79-83.

Ottensmann, J. (1994). Evaluating equity in service delivery in library branches. J. Urban Aff., 16: 109-123.

- (1997). Partially constrained gravity models for predicting spatial interaction with elastic demand. Environ. Plann. A, 29: 975-988.

Ozbay, K., D. Ozmen-Ertekin, and J. Berechman (2003). Empirical analysis of relationship between accessibility and economic development. J. Urban Plann. D-ASCE, 129: 97-119.

Pooler, J. (1994a). A family of relaxed spatial interaction models. Prof. Geogr., 46: 210-217.

— (1994b). An extended family of spatial interaction models. Prog. Hum. Geog., 18: $17-39$.

Shen, Q. (1998). Location characteristics of inner-city neighborhoods and employment accessibility of low-income workers. Environ. Plann. B, 25: 345-365.

Talen, E. and L. Anselin (1998). Assessing spatial equity: An evaluation of measures of accessibility to public playgrounds. Environ. Plann. A, 30: 595-613.

Vickerman, R. (1974). Accessibility, attraction, and potential: A review of some concepts and their use in determining mobility. Environ. Plann. A, 6: 675-691.

Wang, F. (2007). Job access in disadvantaged neighborhoods in Cleveland, 1980-2000: Implications for spatial mismatch and association with crime patterns. Cityscape: A Journal of Policy Development and Research, 9: 95-121.

Wang, F. and W. Minor (2002). Where the jobs are: Employment access and crime patterns in Cleveland. Ann. Assoc. Am. Geogr., 92: 435-450.

Wang, L. and L. Lo (2007). Immigrant grocery-shopping behavior: Ethnic identity versus accessibility. Environ. Plann. A, 39: 684-699.

Willigers, J., H. Floor, and B. van Wee (2007). Accessibility indicators for locational choice of offices: An application to the intraregional distributive effects of high-speed rail in the Netherlands. Environ. Plann. A, 39: 2086-2098.

Wilson, A. (1971). A family of spatial interaction models, and associated developments. Environ. Plann., 3: 1-32.

- (1980). Comments on Alonso's 'theory of movement'. Environ. Plann. A, 12: $727-732$. 


\section{Appendix}

List of variables and definitions:

\begin{tabular}{ll}
\hline$A_{i}$ & Hansen accessibility at origin $i$ \\
$A_{i}^{*}$ & Use-based accessibility to point features at origin $i$ \\
$A_{i}^{* L}$ & Use-based accessibility to linear features at origin $i$ \\
$\alpha$ & Elasticity parameter in use-based accessibility measures \\
$\beta_{0}$ & Constant term in regressions \\
$\beta_{\mathbf{R}}$ & Vector of regression coefficients for respondent characteristics \\
$\beta_{a}$ & Regression coefficient for accessibility \\
$C_{i j}$ & Generalized cost of travel from origin $i$ to destination $j$ \\
$C_{i j}(s)$ & Generalized cost of travel from origin $i$ to location $s$ along linear \\
$C_{i j k}$ & Gestination $j$ \\
$d_{i j}$ & Generalized cost of travel from origin $i$ to segment $k$ on linear destination $j$ \\
$d_{i j k}$ & Distance from origin $i$ to destination $j$ \\
$f\left(C_{i j}\right)$ & Function of generalized cost of travel \\
$\gamma$ & Accessibility coefficient in negative-exponential cost function \\
$\kappa$ & Spatial interaction model parameter \\
$L_{j}$ & Length of linear destination $j$ \\
$L_{j k}$ & Length of segment $k$ on linear destination $j$ \\
$O_{j}$ & Opportunities or attractiveness at destination $j$ \\
$O_{j}(s)$ & Opportunities or attractiveness as function of distance along linear \\
& destination $j$ \\
$O_{j k}$ & Opportunities or attractiveness of segment $k$ on linear destination $j$ \\
$P_{i}$ & Population at origin $i$ \\
$\mathbf{R}_{i}$ & Vector of respondent characteristics for respondent $i$ \\
$s$ & Distance along linear destination \\
$T_{i}$ & Trail use by respondent $i$, either whether used trail or number of times \\
$U_{i}$ & used trail \\
$U_{i j}$ & Use by persons at origin $i$ of facility at destination $j$ \\
\hline & Use by persons at origin $i$ of facility at destination $j$ \\
\hline
\end{tabular}

